\title{
Differences in the Immune Response of the Nonmetastatic Axillary Lymph Nodes between Triple-Negative and Luminal A Breast Cancer Surrogate Subtypes
}

Carlos López, ${ }^{* \dagger}$ Albert Gibert-Ramos, ${ }^{*}$ Ramón Bosch, ${ }^{*}$ Anna Korzynska, ${ }^{\ddagger}$ Marcial García-Rojo, ${ }^{\S}$ Gloria Bueno, Joan Francesc García-Fontgivell, Salomé Martínez González, Laia Fontoura, ${ }^{*}$ Andrea Gras Navarro, ${ }^{*}{ }^{\dagger}$ Esther Sauras Colón, ${ }^{*}$ Júlia Casanova Ribes, ${ }^{*}$ Lukasz Roszkowiak, ${ }^{\ddagger}$ Albert Roso, ${ }^{* *}$ Marta Berenguer, ${ }^{\dagger \dagger}$ Montserrat Llobera, ${ }^{\ddagger}$ Jordi Baucells, ${ }^{\S \S}$ and Marylène Lejeune ${ }^{\star \dagger}$

From the Oncological Pathology and Bioinformatics Research Group, Department of Pathology, ${ }^{*}$ the Knowledge Management Department, ${ }^{\dagger \dagger}$ the Department of Oncology, ${ }^{\ddagger}$ and the Informatics Department, ${ }^{\S \S}$ Hospital de Tortosa Verge de la Cinta, ICS, IISPV, Tortosa, Spain; the Universitat Rovira $i$ Virgili (URV) Campus Terres de l'Ebre, ${ }^{\dagger}$ Tortosa, Spain; the Laboratory of Processing and Analysis of Microscopic Images, ${ }^{\ddagger}$ Nalecz Institute of Biocybernetics and Biomedical Engineering, Polish Academy of Sciences (IBIB PAN), Warsaw, Poland; the Department of Pathology, ${ }^{\S}$ Hospital Universitario Puerta del Mar, Cádiz, Spain; the VISILAB, " Universidad de Castilla-La Mancha, Ciudad Real, Spain; the Department of Pathology," Hospital Universitari Joan XXIII, Tarragona, Spain; and the Institut Universitari d'Investigació en Atenció Primària Jordi Gol (IDIAP Jordi Gol), ** Barcelona, Spain

Accepted for publication November 19, 2020.

Address correspondence to Carlos López, Ph.D, or Albert Gibert-Ramos, Ph.D., Hospital de Tortosa Verge de la Cinta, ICS, IISPV, C/ Esplanetes $\mathrm{n}^{\circ} 14,43500$-Tortosa, Spain. E-mail: clopezp.ebre. ics@gencat.cat or albert. gibert@estudiants.urv.cat.

\begin{abstract}
Breast cancer $(\mathrm{BC})$ comprises four immunohistochemical surrogate subtypes of which triple-negative breast cancer (TNBC) has the highest risk of mortality. Axillary lymph nodes (ALNs) are the regions where BC cells first establish before distant metastasis, and the presence of tumor cells in the ALN causes an immune tolerance profile that contrasts with that of the nonmetastatic $A L N\left(A_{L N}^{-}\right)$. However, few studies have compared the immune components of the $\mathrm{ALNs}^{-}$in BC subtypes. The present study aimed to determine whether differences between immune populations in the primary tumor and $\mathrm{ALNs}^{-}$ were associated with the luminal A or TNBC subtype. We evaluated a retrospective cohort of $144 \mathrm{pa}-$ tients using paraffin-embedded biopsies. The TNBC samples tended to have a higher histologic grade and proliferation index and had higher levels of immune markers compared with luminal $\mathrm{A}$ in primary tumors and $\mathrm{ALNs}^{-}$. Two methods for validating the multivariate analysis found that histologic grade, intratumoral S100 dendritic cells, and CD8 T lymphocytes and CD57 natural killer cells in the $\mathrm{ALNs}^{-}$were factors associated with TNBC, whereas CD83 dendritic cells in the $\mathrm{ALNs}^{-}$were associated with the luminal A subtype. In conclusion, we found that intratumoral regions and $\mathrm{ALNs}^{-}$of TNBC contained higher concentrations of markers related to immune tolerance than luminal A. This finding partially explains the worse prognosis of patients with TNBC. (Am J Pathol 2021, 191: 545-554; https:// doi.org/10.1016/j.ajpath.2020.11.008)
\end{abstract}

Cancer is one of the most prominent of all human diseases, and breast cancer (BC) is the most frequent type in women. ${ }^{1,2}$ Four surrogate subtypes of $\mathrm{BC}$ with distinct clinical behaviors are recognized: luminal A-like, luminal $\mathrm{B}$-like HER2-negative and HER2-positive, HER2-positive (nonluminal), and triplenegative $\mathrm{BC}(\mathrm{TNBC}){ }^{3}$ These subtypes can be distinguished
Supported by Institute of Health Carlos III projects PI1 1/0488 (C.L.) and PI13/02501 (M.L.), the European Union European Regional Development Fund (C.L. and M.L.), AIDPATH FP7-PEOPLE Project 612471 (G.B.), and the Oncology Master Plan for Catalonia (Pla Director d'Oncologia de Catalunya).

C.L. and A.G.R. contributed equally to this work.

Disclosures: None declared. 
by immunohistochemistry (IHC) by quantifying the expression of estrogen receptor (ER), progesterone receptor $(\mathrm{PR})$, and the $H E R 2^{4,5}$ and by determining tumor proliferation, as measured by Ki-67. ${ }^{6}$ TNBC accounts for $10 \%$ to $15 \%$ of all BC cases and has a higher risk of mortality and worse prognosis than the other subtypes. ${ }^{7,8}$ In contrast, $60 \%$ to $70 \%$ of patients with BC present with the luminal A subtype, which has a better prognosis than the other subtypes and tends to relapse later than TNBC (after 5 years versus within 2 to 3 years of first presentation, respectively). ${ }^{9}$

The microenvironment of the tumor, especially that of the immune cell populations, plays a key role in $\mathrm{BC}$ progression and patient outcome. Depending on the BC subtype, the immune system may play one of two roles: defending from cancer progression or stimulating tumoral growth, thereby facilitating the establishment and metastasis of cancer. ${ }^{10,11}$ For instance, TNBC in the primary tumor is more immunogenic than the luminal A subtype ${ }^{12,13}$ and expresses a greater variety of cytokine receptors than do luminal $\mathrm{BC}$ cells as a consequence of its greater invasion and metastasis rates. ${ }^{14}$

In $\mathrm{BC}$, the growing primary tumor can invade nearby tissues and migrate into other regional or distant tissues or organs, where it establishes a new tumor or metastasis, the latter causing most $\mathrm{BC}$ deaths. $\mathrm{BC}$ tumoral cells are known to escape the primary tumor through blood or lymphatic vessels. ${ }^{15}$ In particular, axillary lymph nodes (ALNs) are one of the first regions where BC metastasis becomes established, ${ }^{16}$ and infiltration of ALN by tumoral cells is known to be a poor prognosis factor, ${ }^{17,18}$ which has been linked to the $\mathrm{BC}$ subtypes in various ways. ${ }^{19}$ Although the ALN is particularly important in antitumoral immunity, ${ }^{20}$ and the presence of tumor in the ALNs causes immune tolerance, ${ }^{21-23}$ little research has been performed on the immune response in the ALNs and less still on nonmetastatic ALNs $\left(\mathrm{ALNs}^{-}\right)$. In a previous study, our group found the immune response of $\mathrm{ALNs}^{-}$to be an important factor in ALN metastasis in BC that could be indirectly involved in patient outcome. ${ }^{24}$ Although the immune response is decisive in tumoral progression, ${ }^{10,11}$ few studies have compared the immune markers in the $\mathrm{ALNs}^{-}$from the TNBC and luminal A subtypes.

It is clear that the prognosis, ALN status, and probability of metastatic spread of BC subtypes differ greatly. Moreover, the type of immune response is important in $\mathrm{BC}$ development, and the immune response in the ALN may be involved in tumor progression, even in the $\mathrm{ALN}^{-}$. Given this evidence, we compared the expression of specific immune populations by IHC in patients with BC diagnosed with luminal A and TNBC in the intratumoral microenvironment and in the $\mathrm{ALNs}^{-}$and investigated their association with the BC subtype. To our knowledge, this is the first comparison of the immune response in the $\mathrm{ALNs}^{-}$of the two subtypes.

\section{Materials and Methods}

\section{Study Design and Participants}

A retrospective cohort of patients diagnosed with invasive breast carcinoma of no special type during 2000 to 2008 were evaluated. Of the 144 patients with $\mathrm{BC}$ evaluated, 88 were diagnosed as having luminal $\mathrm{A}(61 \%)$ and 56 as having TNBC (39\%) subtypes. Regarding the treatments administered, $12.5 \%$ of patients with the luminal A subtype and $9.1 \%$ of patients with the TNBC subtype received neoadjuvant therapy, $98.9 \%$ of patients with the luminal A subtype and 100\% of patients with the TNBC subtype received adjuvant therapy (hormonal therapy and/or chemotherapy), and $80.7 \%$ of patients with the luminal A subtype and $85.5 \%$ of the patients with TNBC received radiotherapy. Biopsy specimens were obtained from the primary tumors and $\mathrm{ALNs}^{-}$to evaluate 11 immune populations. The biopsy specimens were collected from the Tumor Bank of the Pathology Department of the Hospital of Tortosa Verge de la Cinta and the Hospital Joan XXIII of Tarragona (Spain). All the biopsy specimens were reviewed using a new hematoxylin-eosin slide to check tissue availability.

The Ethics Committee of the Hospital Joan XXIII of Tarragona and the Research Committee of Hospital of Tortosa Verge de la Cinta approved this study (reference number 24p/2012). All patients provided written informed consent to participate in the study and for their biopsy specimens and clinical data to be used. The Strengthening the Reporting of Observational Studies in Epidemiology (STROBE) guidelines were followed.

\section{TMA Construction and IHC}

Pathologists selected four representative areas to obtain four 2-mm cylinders: two from the primary tumor biopsy specimens (intratumoral region) and two from the central region of $\mathrm{ALN}^{-}$biopsy specimens. This gave a total of 576 cylinders (352 from patients with luminal A subtype and 224 from patients with TNBC), which were incorporated into tissue microarrays (TMAs) as previously described. ${ }^{25} \mathrm{~A}$ total of 12 TMAs were examind and each TMA block contained 50 cylinders. Eleven slides were sectioned from each TMA, one for each of the 11 immune markers studied, producing a total of 132 slides. TMAs allow the evaluation of a large number of cases, but with the drawback that they are not closely correlated with whole-tissue sections to permit clinical diagnosis. Even so, their use for research purposes is considered adequate ${ }^{26}$ and a PubMed search of TMAs in breast cancer yielded $>200$ articles, which is an indication of their popularity for studying the immune response in $\mathrm{BC} .^{27,28}$

For the immunohistochemical detection in the immune cell populations studied here, the following primary antibodies (Figure 1) were used: T helper lymphocytes (anti-CD4, clone 4B12, Dako, Santa Clara, CA), cytotoxic T lymphocytes (anti-CD8, clone C8/144B, Dako), natural killer (NK) cells (anti-CD57, clone NK1, Zymed, Thermo Fisher Scientific, Waltham, MA), regulatory $\mathrm{T}$ cells [anti-forkhead box protein P3 (FOXP3), clone 236A/E7, CNIO, Madrid, Spain], macrophages (anti-CD68, clone KP1, Dako), follicular dendritic cells (DCs) (anti-CD21, clone 1F8, Dako), Langerhans DCs 
(anti-CD1a, clone 010, Dako), plasmacytoid DCs (antiCD123, clone 6H6, eBioscience, San Diego, CA), interdigitant DCs (anti-S100, polyclonal, Leica Microsystems GmbH, Wetzlar, Germany), lysosome-associated membrane glycoprotein 3 (LAMP3) DCs (anti-CD208, polyclonal, Proteintech, Rosemont, IL), and mature DCs (anti-CD83, clone1H4b, Leica Microsystems $\mathrm{GmbH}$ ). The final detection of the staining was performed using the ENDVISION FLEX method (Dako), with the chromogen diaminobenzidine (Dako) as a substrate and hematoxylin as counterstain, in accordance with the manufacturer's protocol.

Slides were scanned at $\times 40$ magnification with the Aperio ScanScope XT scanner (Leica Microsystems GmbH, Nussloch, Germany). TIFF digital images were obtained at a resolution of $0.25 \mu \mathrm{m}$ per pixel and with an approximate size of $25 \mathrm{~GB}$. This method for obtaining these types of image is known as whole slide imaging and is the most recent imaging modality in the field of pathology. ${ }^{29}$ To analyze images correctly, each cylinder was individually examined in a single image with automatic tools previously developed by our team. ${ }^{30,31}$ These 6336 individual digital images (11 immune markers $\times 576$ cylinders) were stored in TIFF format with a size of approximately $500 \mathrm{MB}$ and coded with the case number and name of the corresponding immune marker. Each cylinder area and its respective immune markers were evaluated by digital image analytical procedures, as previously described.
The following clinical and pathologic data were compiled: age, tumor diameter, number of metastatic lymph nodes, presence of axillar metastasis, lymphovascular invasion, perineural invasion, histologic grade, proliferation index (Ki-67), and menopausal status. These variables were compared in patients with the luminal $\mathrm{A}$ and TNBC subytpes.

\section{Statistical Analysis}

To evaluate the differences in the mean or median concentrations of the studied immune populations and the differences in the quantitative clinical and pathologic variables between the two BC subtypes, independent-samples $t$-test or the $U$-test were used. Categorical clinical and pathologic variables were examined using the $\chi^{2}$ or Fisher exact test.

To assess which of the immunologic, clinical, and pathologic variables were associated with each of the studied subtypes (with luminal A as reference), univariate logistic regression models were fitted for each variable to estimate the odds ratio (OR) and $95 \% \mathrm{CI}$. These models allowed us to identify the studied variables differentially associated with the TNBC and luminal A subtypes. The variables attaining a level of significance of $P<0.10$ in the univariate analyses to develop a multivariate logistic regression model. Model goodness of fit was concluded if the HosmerLemeshow test was nonsignificant for all the variables.
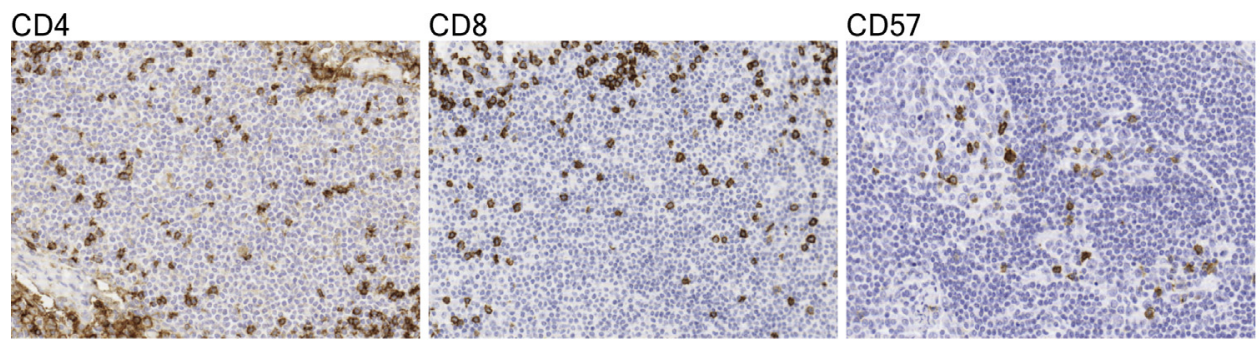

FOXP3

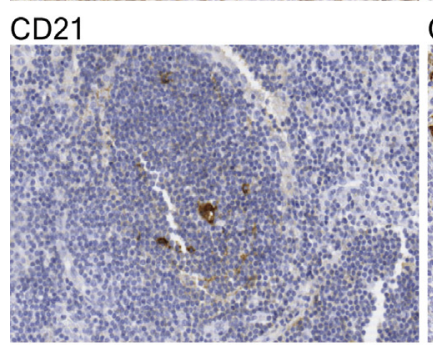

CD68

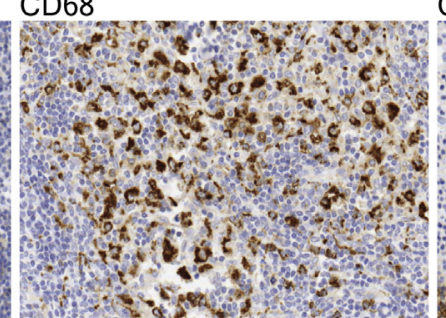

CD1a
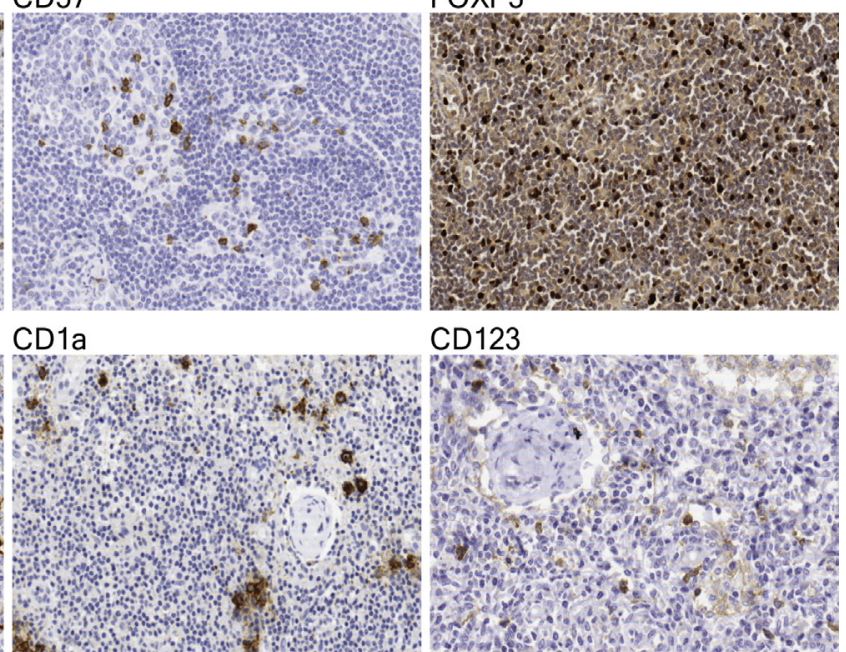

CD123

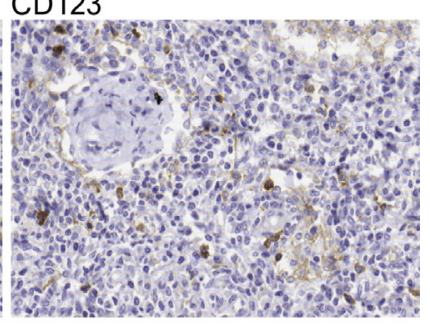

CD83
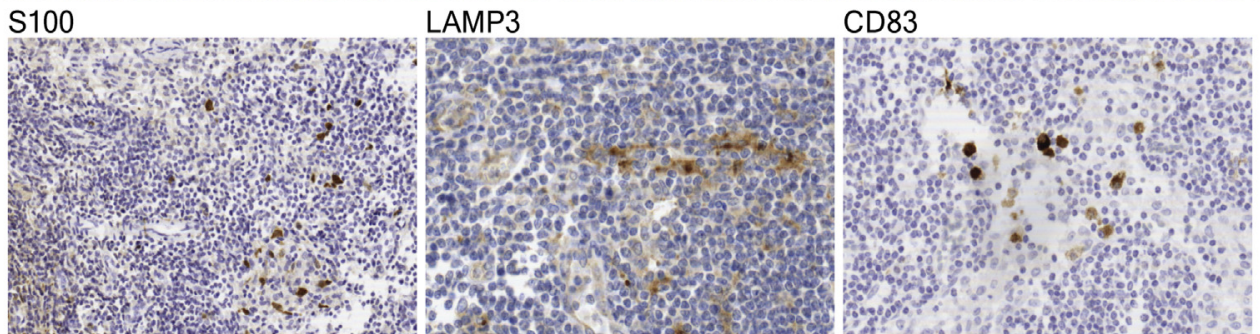

Figure 1 Immunohistochemical staining patterns for the immune markers in formalin-fixed, paraffin-embedded sections. Representative examples of membrane (CD4, CD8, CD21), cytoplasmic [CD68, CD123, lysosome-associated membrane glycoprotein (LAMP3)], membrane and/or cytoplasmic (CD57, CD1a, CD83), nuclear and/or cytoplasmic (S100), and nuclear [forkhead box protein P3 (FOXP3)] reactivity of the biomarkers. Original magnification, $\times 40$. 
Any quantitative variable that was significant in the univariate analysis that contributed to the goodness of fit of the model was dichotomized according to its distribution: greater than or less than/equal to the mean (normally distributed variable) or median (non-normally distributed variable). As a rule of thumb, a logistic regression should be based on a minimum of 10 events for each variable included in the model. ${ }^{35,36}$ Luminal $\mathrm{A}$ was used as the reference group in the analyses, with TNBC as the event. With a final multivariate model that included 4 variables, the sample size of 57 events was therefore considered sufficient. The ability of the model to correctly assign patients to the luminal A or TNBC subtype was evaluated using Nagelkerke's $R^{2}$, the sensitivity and specificity, and the area under the receiver operating characteristic curve (AUC).

The model obtained was validated by two statistical techniques. The first validation was performed with the bootstrapping simulation technique using IBM SPSS Statistics version 23.0 (IBM, Armonk, NY), assuming a 95\% CI and using 10,000 samples. The second validation used the Multiple Imputation method of Stata software version 14.0 (StataCorp LLC, College Station, TX). Ten imputed data sets were used to handle missing data, and all the potential predictive variables and outcomes were included in the imputation model. Rubin's rules were used to combine logistic model estimates and SEs. The AUC was calculated for both validation methods. $P<0.05$ was considered statistically significant for all analyses.

\section{Results}

\section{Patients' Clinical and Pathologic Data}

Table 1 summarizes the differences in the clinical and pathologic characteristics between the patients with the luminal A and TNBC subtypes. As expected, patients with TNBC had a significantly greater proportion of higher histologic grades than those in the luminal A group. Similarly, the TNBC group also had a greater percentage of patients with a high level of Ki-67 expression.

\section{Immune Cell Markers}

The immune microenvironment of the intratumoral region in the TNBC group had a statistically significantly higher concentration of the CD4, CD8, FOXP3, CD21, CD68, CD1a, CD123, S100, and CD208 markers than the luminal A subtype (Table 2). Nine of the 11 immune populations studied differed between subtypes with respect to concentrations in the intratumoral area. The $\mathrm{ALNs}^{-}$had similar

Table 1 Differences in the Clinical and Pathologic Variables between Patients with Luminal A and Triple-Negative Molecular Breast Cancer Profiles

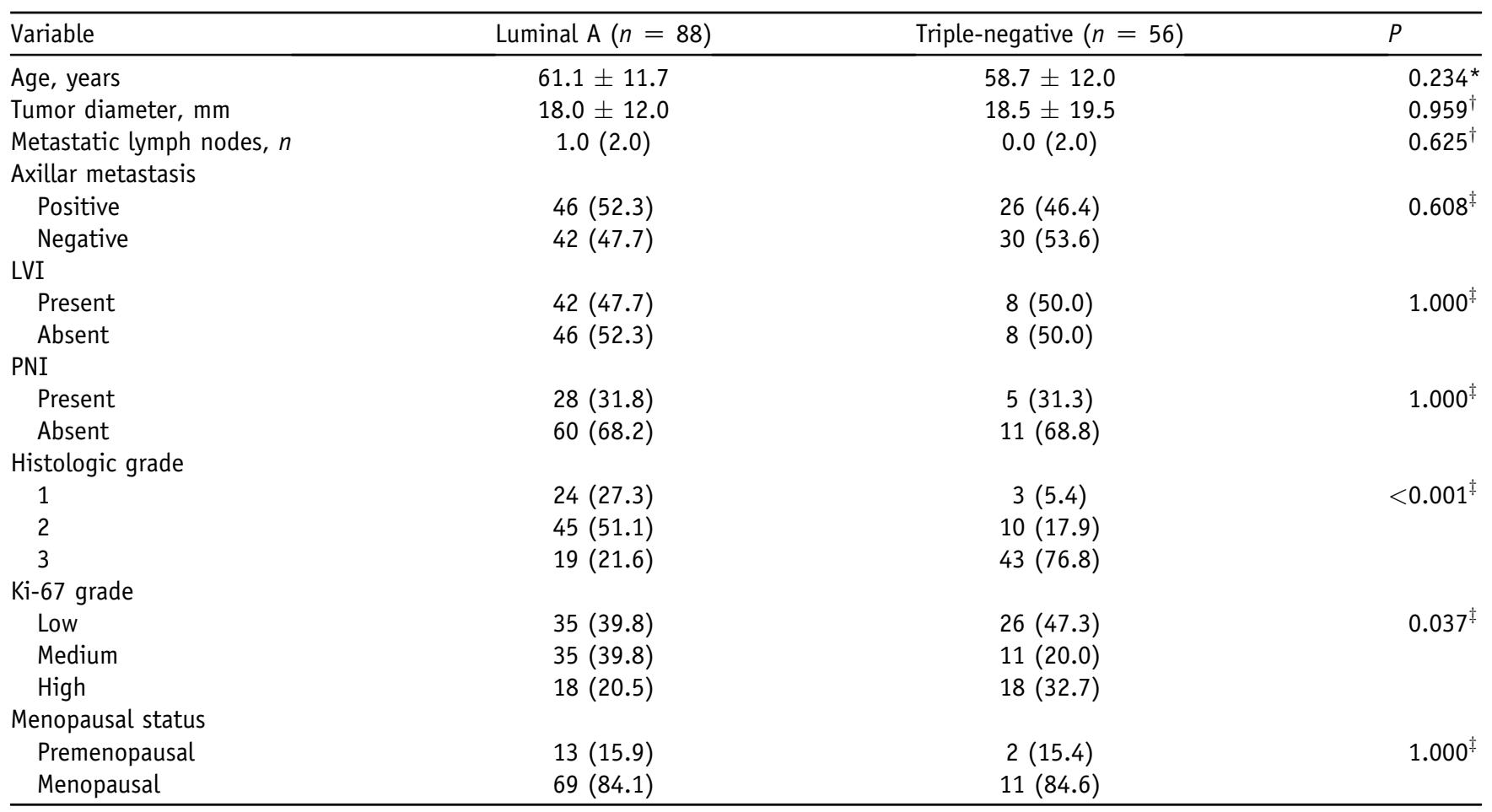

Data are expressed as means \pm SD for age and tumor diameter, as median (interquartile range) for number of metastatic lymph nodes, and as $n$ (\%) for the rest of the data.

*Independent-samples $t$-test.

${ }^{\dagger} U$-test.

The $\chi^{2}$ or Fisher exact test.

LVI, lymphovascular invasion; PNI, perineural invasion. 
results to those of the intratumoral region, with higher concentrations of CD4, CD8, CD57, and CD123 markers in the TNBC group. Conversely, CD83 tended to be present at significantly higher concentrations in the luminal A group than in the TNBC group.

\section{Logistic Regression}

The associations of each variable with the tumor subtype estimated in univariate logistic regressions are presented in Table 3. To evaluate which of the variables were independently associated with each subtype, all the variables with an associated $P<0.10$ in the univariate analyses were considered in the multivariate logistic regression model. The multivariate model (Table 3) indicated that none of the clinical or pathologic factors was independently associated with the TNBC when the immunologic variables were also considered in the analysis. On the other hand, regarding the immune populations, the model found that higher concentrations of intratumoral S100, interdigitant DCs, CD8 cytotoxic T lymphocytes, and CD57 NK cells in the ALNs ${ }^{-}$ were factors independently associated with the TNBC subtype. CD83 mature DCs in the $\mathrm{ALNs}^{-}$were also a protective factor in the TNBC subtype. The Hosmer-Lemeshow test was not significant $(P=0.839)$, indicating a good fit.

Nagelkerke's $R^{2}$ for the model was 0.732 , which means that approximately three-quarters of the variation between the subtypes may be explained by the immune response of the primary tumor and $\mathrm{ALNs}^{-}$. The receiver operating characteristic curve (Figure 2) indicated that the multivariate model had a sensitivity of $81.3 \%$ and a specificity of $91.0 \%$. Its AUC was $0.956(95 \%$ CI, 0.916-0.995).

Of the two methods used to validate the multivariate model, the bootstrap simulation produced results similar to those of the unvalidated multivariate model. The S100 immune marker in the intratumoral region had an OR of 2.04 (95\% CI, $1.10-3.79 ; P=0.024)$. The ORs for the immune markers in the $\mathrm{ALNs}^{-}$were as follows: $1.15(95 \% \mathrm{CI}$, $1.04-1.28 ; \quad P=0.002)$ for $\mathrm{CD} 8,23.23(95 \% \mathrm{CI}$, 4.76-113.30; $P<0.001)$ for CD57, and $0.052(95 \% \mathrm{CI}$, $0.012-0.23 ; P<0.001)$ for CD83. The Hosmer-Lemeshow test was not significant $(P=0.773)$, indicating a good fit. The AUC was 0.960 (95\% CI, 0.960-0.961) (Figure 2) with a Nagelkerke's $R^{2}$ of 0.746 . The validation of the multivariate model by multiple imputation confirmed the immune populations of the $\mathrm{ALNs}^{-}$in the unvalidated model: $\mathrm{OR}=1.12(95 \% \mathrm{CI}, 1.04-1.21 ; P=0.004)$ for $\mathrm{CD} 8 ; \mathrm{OR}=15.40(95 \% \mathrm{CI}, 3.10-76.60 ; P=0.001)$ for CD57, fitted as a continuous variable because, after multiple imputation, the Hosmer-Lemeshow test indicated it had a good fit; and 0.19 (95\% CI, 0.07-0.51; $P<0.001$ ) for CD83. The intratumoral S100 immune population was not significant and was therefore not included in the final model. On the other hand, histologic grade was significant in the validated model: $\mathrm{OR}=2.01(95 \%$ CI, 0.21-19.33;
Table 2 Differences in the Concentration of the Immune Populations in the Intratumoral and $\mathrm{ALN}^{-}$Regions between Patients with Luminal A and TNBC Subtypes

\begin{tabular}{lccr}
\hline & Luminal A & \multicolumn{1}{l}{ TNBC } \\
Variable & $(n=88)$ & $(n=56)$ & \multicolumn{1}{c}{$P$} \\
\hline Intratumoral & & & \\
CD4 & $0.61(1.11)$ & $3.34(7.15)$ & $<0.001^{*}$ \\
CD8 & $1.06(1.53)$ & $1.54(3.31)$ & $0.050^{*}$ \\
CD57 & $0.10(0.33)$ & $0.12(0.24)$ & $0.993^{*}$ \\
F0XP3 & $0.06(0.13)$ & $0.17(0.31)$ & $<0.001^{*}$ \\
CD21 & $0.001(0.027)$ & $0.006(0.017)$ & $0.021^{*}$ \\
CD68 & $2.63(2.16)$ & $3.69(4.46)$ & $<0.001^{*}$ \\
CD1a & $0.09(0.20)$ & $0.22(0.68)$ & $0.009^{*}$ \\
CD123 & $0.000(0.000)$ & $0.035(0.099)$ & $<0.001^{*}$ \\
S100 & $0.12(0.29)$ & $0.32(0.62)$ & $0.002^{*}$ \\
CD208 & $0.02(0.08)$ & $0.07(0.15)$ & $0.015^{*}$ \\
CD83 & $0.11(0.18)$ & $0.11(0.26)$ & $0.650^{*}$ \\
ALN ${ }^{-}$ & & & \\
CD4 & $56.25 \pm 13.30)$ & $63.32 \pm 14.24)$ & $0.004^{\dagger}$ \\
CD8 & $13.07(8.47)$ & $19.45(8.35)$ & $<0.001^{*}$ \\
CD57 & $0.18(0.23)$ & $0.76(0.82)$ & $<0.001^{*}$ \\
F0XP3 & $1.99(1.42)$ & $2.12(1.64)$ & $0.927^{*}$ \\
CD21 & $0.70(1.76)$ & $1.01(1.17)$ & $0.539^{*}$ \\
CD68 & $9.32(4.93)$ & $9.91(6.82)$ & $0.225^{*}$ \\
CD1a & $1.64(3.49)$ & $1.76(3.19)$ & $0.797^{*}$ \\
CD123 & $1.32(1.84)$ & $2.35(3.13)$ & $0.001^{*}$ \\
S100 & $4.16(5.40)$ & $3.95(4.48)$ & $0.621^{*}$ \\
CD208 & $0.24(0.41)$ & $0.18(0.27)$ & $0.112^{*}$ \\
CD83 & $1.07(1.26)$ & $0.19(0.59)$ & $<0.001^{*}$ \\
\hline & & &
\end{tabular}

Data are expressed as means \pm SD or median (interquartile range) of the percentage of positive stained area expressed for each marker.

*U-test.

${ }^{\dagger}$ Independent-samples $t$-test.

$\mathrm{ALN}^{-}$, nonmetastatic axillary lymph node; FOXP3, forkhead box protein P3; TNBC, triple-negative breast cancer.

$P=0.547$ ) for grade 2 and 12.27 (95\% CI, 1.39-108.17; $P=0.024)$ for grade 3 . The Hosmer-Lemeshow test indicated a good fit $(P=0.466)$. The model had an AUC of 0.940 (95\% CI, 0.898-0.982) (Figure 2) and a Nagelkerke's $R^{2}$ of 0.716 . Thus, the significant associations in the multivariate model of the three immune populations with TNBC in the $\mathrm{ALNs}^{-}$were confirmed by both validation methods.

\section{Discussion}

Most studies in this field have compared metastatic ALNs $\left(\mathrm{ALNs}^{+}\right.$) with primary tumor or with $\mathrm{ALNs}^{-37}$; however, not many have compared the immune response in $\mathrm{ALNs}^{-}$of different types of patients with BC. ${ }^{24,38}$ Thus, we evaluated the differences in immune cell markers in the intratumoral region and $\mathrm{ALNs}^{-}$of patients with luminal $\mathrm{A}$ and TNBC subtype invasive BCs. We found that the TNBC subtype had more aggressive features, a higher histologic grade, and a higher proliferation index than luminal $\mathrm{A}$ as noted in 
Table 3 Univariate and Multivariate Analysis of the Differences in Variables in TNBC Compared with Luminal A Subtype

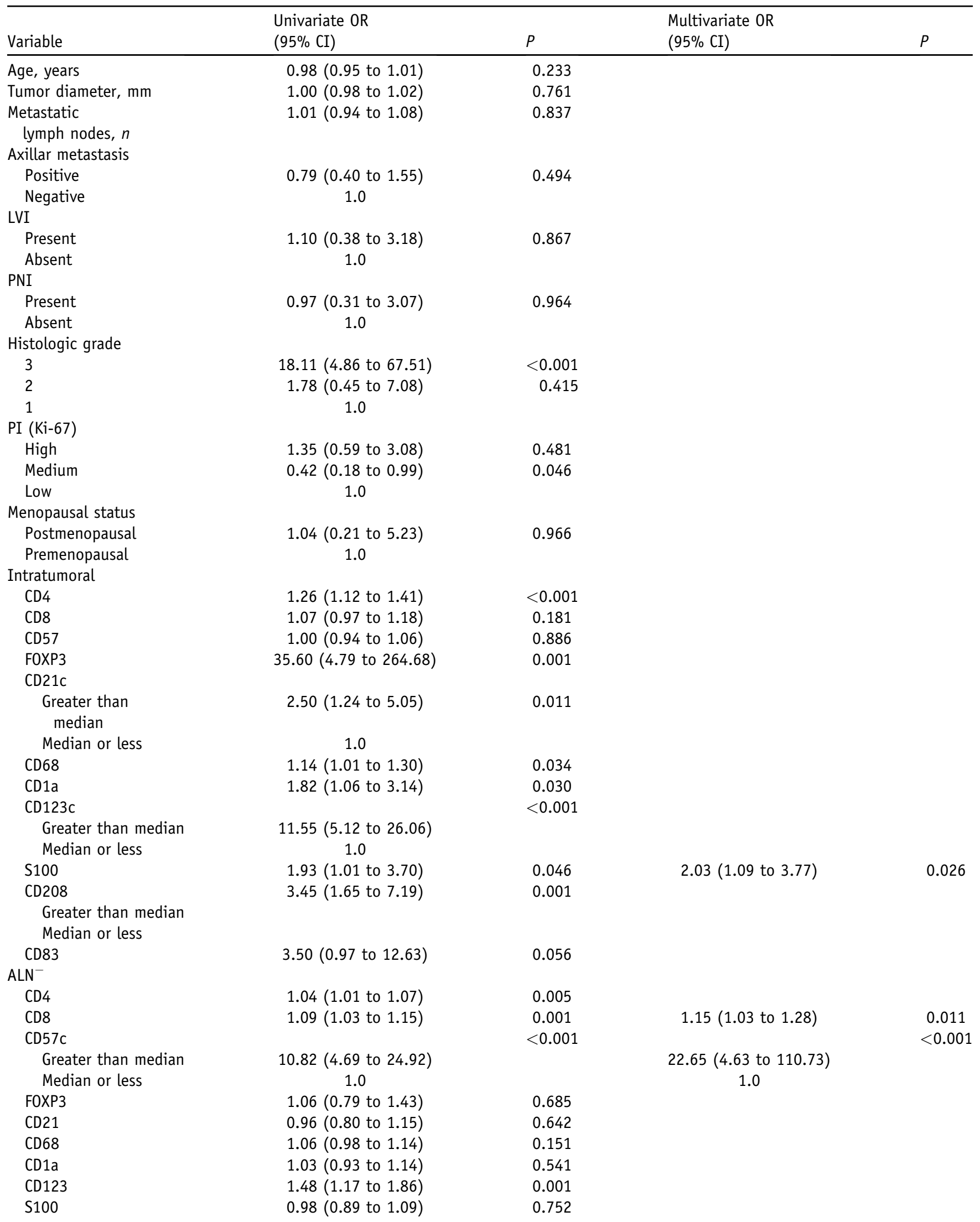


Table 3 (continued)

\begin{tabular}{clcl}
\hline & $\begin{array}{l}\text { Univariate OR } \\
(95 \% \mathrm{CI})\end{array}$ & $\begin{array}{l}\text { Multivariate OR } \\
(95 \% \mathrm{CI})\end{array}$ \\
\hline CD208 & $0.42(0.14$ to 1.24$)$ & 0.116 & \\
CD83 & $0.15(0.07$ to 0.32$)$ & $<0.001$ & $0.053(0.012$ to 0.239$)$ \\
\hline
\end{tabular}

$\mathrm{ALN}^{-}$, nonmetastatic axillary lymph node; FOXP3, forkhead box protein P3; LVI, lymphovascular invasion; OR, odds ratio; PNI, perineural invasion; TNBC, triple-negative breast cancer.

earlier studies. ${ }^{7,39-41}$ Some studies have reported the metastatic status of the ALNs to be more closely associated with the TNBC than the luminal A subtype. ${ }^{39,40,42-48}$ Other authors have noted that TNBC cases have a similar ${ }^{49}$ or a lower $^{50}$ probability of developing ALN metastasis than other subtypes, but we did not find any significant differences in the proportion of $\mathrm{ALN}^{+}$between the two groups. Apart from the histologic differences, the immune response in the tumor is also known to differ according to the $\mathrm{BC}$ subtype because the TNBC subtype more strongly activates the immune system than does luminal A. ${ }^{12}$ We found clear differences between the subtypes, whereby a significantly higher proportion of stained cells in nine of the 11 immune populations studied were present in the intratumoral region of the TNBC. Similar results were found in the $\mathrm{ALNs}^{-}$, where four immune populations had a higher proportion of stained cells in the TNBC group and one was at a higher proportion in the luminal A group. Although fighting cancer is a primary function of the immune cells, cancer promotes immunosuppression; thus, immune cells may shift their action toward tolerance to cancer. ${ }^{51,52}$ Six of the 11 studied markers that were highly expressed in TNBC samples could be directly or indirectly linked to tolerance to cancer. Several studies ${ }^{53-57}$ have suggested that CD123 DCs and $\mathrm{FOXP}^{+}$cells stimulate tolerance of tumoral cells. Controversies surround the role of CD4 and CD8 in cancer progression, but some studies have reported that they

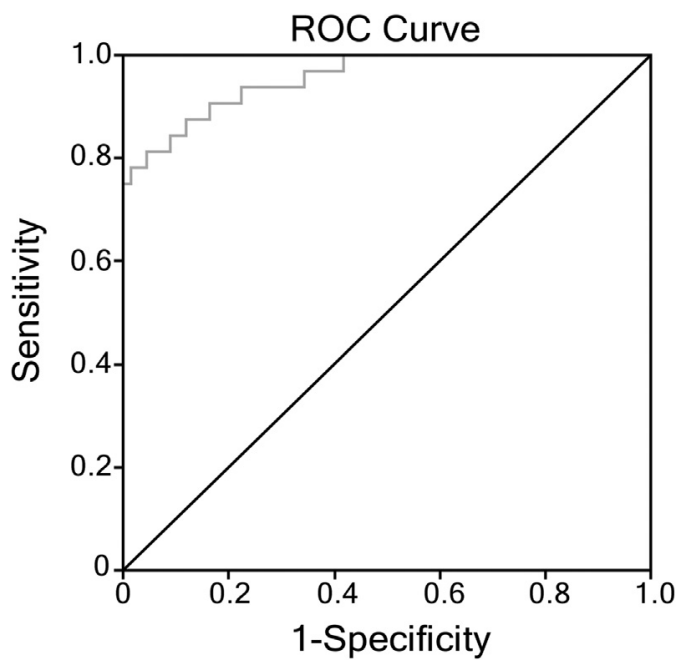

Figure 2 Receiver-operating characteristic (ROC) curve for the multivariate logistic regression model prediction. contribute to a worse outcome..$^{58-60}$ In addition, a high density of $\mathrm{CD} 8^{+}$tumor-associated macrophages and S100 expression have been linked to worse outcome. ${ }^{61,62}$ This finding is consistent with our findings and indicates that immune cells in TNBC may become tumor tolerant and promote poor prognosis.

Considering the factors associated with each intrinsic subtype, we found that some immune cell populations in the intratumoral region and in the $\mathrm{ALN}^{-}$were more strongly associated with the subtypes than the well-established pathologic factors. We noted this strong association in prior studies of immune populations associated with the occurrence of metastasis in the ALN. ${ }^{24}$ Nevertheless, as previously discussed, this association does not mean that immune cell populations are more important than the pathologic factors used for predicting patient outcome, but that they are complementary and could also be associated with patient outcome. This association is evident from the multivariate model in which we found immune populations to be associated only with the $\mathrm{BC}$ subtypes, whereas the pathologic factors proved not significant. At the intratumoral level, only higher concentrations of interdigitant S100 DCs were associated with the TNBC subtype. These DCs are derived from bone marrow and located in the T-cell domains of various humans tissues. ${ }^{63}$ S100 gene expression is more active in the basal than in the nonbasal BC subtype, and although S100 proteins are a diverse group, the expression of most of them is linked to worse outcomes. ${ }^{62}$ Regarding the $\mathrm{ALNs}^{-}$, higher concentrations of $\mathrm{CD}^{+}{ }^{+} \mathrm{T}$ lymphocytes and $\mathrm{CD} 57^{+} \mathrm{NK}$ cells were significantly associated with the TNBC, whereas higher proportions of mature $\mathrm{CD} 3^{+}$DCs were associated with the luminal A subtype. In the intratumoral area, tumoral cells directly affect the microenvironment, modulating the immune response, whereas metastasis has not yet been established in the $\mathrm{ALNs}^{-}$, so the immune responses are expected to be different. Even so, some studies have provided evidence that the primary tumor alters the immune microenvironment in the ALNs even before establishing metastasis. ${ }^{23,38} \mathrm{Hu}$ et $\mathrm{al}^{64}$ suggested that NK (CD57) cells are associated with better clinical outcomes in a variety of solid tumors, but they did not include BCs in their study. Although overall survival or relapse-free survival cannot be estimated, as explained earlier, TNBCs are typically more aggressive and have a worse prognosis than luminal A BCs, which makes it difficult to explain the higher proportion of $\mathrm{CD} 57^{+} \mathrm{NK}$ cell; however, it might be related to the increased 
immunogenicity of TNBCs. Moreover, although the presence of $\mathrm{CD} 57^{+} \mathrm{NK}$ cells indicates a possible better prognosis in solid tumors, the nature of their involvement in the $\mathrm{ALNs}^{-}$might not be the same. Indeed, Rezaeifard et $\mathrm{al}^{65}$ recently found that the presence of NK lymphocytes in the tumor draining lymphatic nodes was associated with poor prognosis in patients with BC. Similarly, although controversy persists regarding the association of $\mathrm{CD}^{+} \mathrm{T}$ lymphocytes with better or worse prognosis, ${ }^{58,59,66-68}$ their presence in TNBC is usually associated with increased patient survival. ${ }^{69,70}$ Some authors have suggested that the differences between subtypes arise because highly proliferative cancers, such as TNBC, develop a stronger immune response. ${ }^{70}$ Accumulation of $\mathrm{CD} 7^{+}$and $\mathrm{CD} 8^{+} \mathrm{T}$ cells occurs frequently in individuals with various forms of cancer and has been linked to reduced survival. ${ }^{71-75}$ Our study found an association of $\mathrm{CD} 8^{+} \mathrm{T}$ lymphocytes and $\mathrm{CD} 7^{+} \mathrm{NK}$ cells in the $\mathrm{ALNs}^{-}$with the TNBC, possibly because of the greater proliferation of this subtype. This occurrence explains the stronger immunogenicity, which could also have occurred because the $\mathrm{ALNs}^{-}$are not sufficiently affected by the immune escape component of the immunoediting process of tumoral growth by that stage. This finding means that neither the immune resistance of tumoral cells nor the down-regulation of effector cells, such as $\mathrm{CD}^{+}$lymphocytes, that typically occurs in advanced tumors, may have affected the ALNs ${ }^{-} .{ }^{76}$ In addition, most of the studies of the immune response have focused on primary tumors; therefore, the role of these immune cells in the ALNs, in particular the $\mathrm{ALNs}^{-}$, might differ.

The expression of mature $\mathrm{CD} 83^{+}$DCs is regarded as an independent prognostic marker of survival, ${ }^{77}$ which is consistent with the higher concentration we observed in the $\mathrm{ALNs}^{-}$of the luminal A subtype. Overall, our results suggest that the $\mathrm{ALN}^{-}$is an active immunogenic region where the immune response to cancer develops. On the other hand, validating our multivariate model by multiple imputation led to the inclusion of histologic grade as an independently significant factor. As previously explained, higher histologic grade may be linked to the greater aggressivity of the $\mathrm{TNBC}^{7}$ although, in our study, the immune markers were closely associated with the $\mathrm{BC}$ subtypes. This finding indicates that the $\mathrm{BC}$ subtype not only affects these clinical and pathologic parameters but also strongly affects the immune response, particularly in the $\mathrm{ALNs}^{-}$. Moreover, S100 (in one of the two validations) in the intratumoral region and the CD8, CD57, and CD83 markers in the $\mathrm{ALNs}^{-}$(in both validations) are independent factors associated with the TNBC subtype, which suggests that they may be good predictors of the BC subtype. The ability to predict the $\mathrm{BC}$ subtype clearly illustrates how the immune response in the $\mathrm{ALNs}^{-}$can be associated with each subtype.

In conclusion, our results indicate that the luminal A and TNBC subtypes clearly differ with respect to their proportions of immune markers, not only in the primary tumor, as expected, but also in the $\mathrm{ALNs}^{-}$, an aspect that has not been previously studied. TNBC has a more active immune response, with an emphasis on the markers related to immune tolerance, in the intratumoral region and in the $\mathrm{ALNs}^{-}$, which might be related to its poorer prognosis and histologic grade. These results are significant because they highlight the importance of the immune response of the $\mathrm{ALNs}^{-}$in cancer progression. One of the limitations of IHC is that using single IHC markers for specific immune populations could lead to them being overestimated. Nevertheless, our results clarify the differences in the composition of the immune cells in the $\mathrm{ALNs}^{-}$. Further studies are required to fully establish the specific type of the immune cells in the $\mathrm{ALN}^{-}$and their role in the survival and relapse of patients with $\mathrm{BC}$.

\section{Acknowledgments}

We thank Barbara Tomàs, Vanesa Gestí, María del Mar Barbera, Anna Curto, Noelia Burgues, Ainhoa Montserrat, Eduard Nolla, Maria Fortuny, Sandra Bages, Mireia Sueca, and Marc Iniesta for their skillful technical assistance.

\section{Author Contributions}

C.L. is the guarantor of this work and, as such, had full access to all the data in the study and takes responsibility for the integrity of the data and the accuracy of the data analysis.

\section{References}

1. Ferlay J, Soerjomataram I, Dikshit R, Eser S, Mathers C, Rebelo M, Parkin DM, Forman D, Bray F: Cancer incidence and mortality worldwide: sources, methods and major patterns in GLOBOCAN 2012. Int J Cancer 2015, 136:E359-E386

2. Siegel RL, Miller KD, Jemal A: Cancer statistics, 2020. CA Cancer J Clin 2020, 70:7-30

3. Goldhirsch A, Winer EP, Coates AS, Gelber RD, Piccart-Gebhart M, Thurlimann B, Senn HJ: Personalizing the treatment of women with early breast cancer: highlights of the St Gallen International Expert Consensus on the primary therapy of early breast cancer 2013. Ann Oncol 2013, 24:2206-2223

4. Hon JD, Singh B, Sahin A, Du G, Wang J, Wang VY, Deng FM, Zhang DY, Monaco ME, Lee P: Breast cancer molecular subtypes: from TNBC to QNBC. Am J Cancer Res 2016, 6:1864-1872

5. Cho N: Molecular subtypes and imaging phenotypes of breast cancer. Ultrasonography 2016, 35:281-288

6. Harbeck N, Gnant M: Breast cancer. Lancet 2017, 389:1134-1150

7. Foulkes WD, Smith IE, Reis-Filho JS: Triple-negative breast cancer New Engl J Med 2010, 363:1938-1948

8. Li X, Yang J, Peng L, Sahin AA, Huo L, Ward KC, O’Regan R, Torres MA, Meisel JL: Triple-negative breast cancer has worse overall survival and cause-specific survival than non-triple-negative breast cancer. Breast Cancer Res Treat 2017, 161:279-287

9. Harbeck N, Penault-Llorca F, Cortes J, Gnant M, Houssami N, Poortmans P, Ruddy K, Tsang J, Cardoso F: Breast cancer. Nat Rev Dis Primers 2019, 5:66 
10. Coleman RE, Gregory W, Marshall H, Wilson C, Holen I: The metastatic microenvironment of breast cancer: clinical implications. Breast 2013, 22(Suppl 2):S50-S56

11. Nagarajan D, McArdle SEB: Immune landscape of breast cancers. Biomedicines 2018, 6:20

12. Garcia-Teijido P, Cabal ML, Fernandez IP, Perez YF: Tumor-infiltrating lymphocytes in triple negative breast cancer: the future of immune targeting. Clin Med Insights Oncol 2016, 10:31-39

13. Liu Z, Li M, Jiang Z, Wang X: A comprehensive immunologic portrait of triple-negative breast cancer. Transl Oncol 2018, 11:311-329

14. Levano KS, Jung EH, Kenny PA: Breast cancer subtypes express distinct receptor repertoires for tumor-associated macrophage derived cytokines. Biochem Biophys Res Commun 2011, 411:107-110

15. Scully OJ, Bay BH, Yip G, Yu Y: Breast cancer metastasis. Cancer Genom Proteom 2012, 9:311-320

16. Valente AL, Kane JL, Ellsworth DL, Shriver CD, Ellsworth RE: Molecular response of the axillary lymph node microenvironment to metastatic colonization. Clin Exp Metastasis 2014, 31:565-572

17. Beenken SW, Urist MM, Zhang Y, Desmond R, Krontiras H, Medina H, Bland KI: Axillary lymph node status, but not tumor size, predicts locoregional recurrence and overall survival after mastectomy for breast cancer. Ann Surg 2003, 237:732-738, [discussion: 738-739]

18. Lale Atahan I, Yildiz F, Ozyigit G, Sari S, Gurkaynak M, Selek U, Hayran M: Percent positive axillary lymph node metastasis predicts survival in patients with non-metastatic breast cancer. Acta Oncol 2008, 47:232-238

19. He ZY, Wu SG, Yang Q, Sun JY, Li FY, Lin Q, Lin HX: Breast cancer subtype is associated with axillary lymph node metastasis: a retrospective cohort study. Medicine 2015, 94:e2213

20. Kim R, Emi M, Tanabe K, Arihiro K: Immunobiology of the sentinel lymph node and its potential role for antitumour immunity. Lancet Oncol 2006, 7:1006-1016

21. Chang AY, Bhattacharya N, Mu J, Setiadi AF, Carcamo-Cavazos V, Lee GH, Simons DL, Yadegarynia S, Hemati K, Kapelner A, Ming Z, Krag DN, Schwartz EJ, Chen DZ, Lee PP: Spatial organization of dendritic cells within tumor draining lymph nodes impacts clinical outcome in breast cancer patients. J Transl Med 2013, 11:242

22. Faghih Z, Erfani N, Haghshenas MR, Safaei A, Talei AR, Ghaderi A: Immune profiles of CD4+ lymphocyte subsets in breast cancer tumor draining lymph nodes. Immunol Lett 2014, 158:57-65

23. Mansfield AS, Heikkila PS, Vaara AT, von Smitten KA, Vakkila JM, Leidenius MH: Simultaneous Foxp3 and IDO expression is associated with sentinel lymph node metastases in breast cancer. BMC Cancer 2009, 9:231

24. Lopez C, Bosch R, Orero G, Korzynska A, Garcia-Rojo M, Bueno G, Fernandez-Carrobles MDM, Gibert-Ramos A, Roszkowiak L, Callau C, Fontoura L, Salvado MT, Alvaro T, Jaen J, RosoLlorach A, Llobera M, Gil J, Onyos M, Plancoulaine B, Baucells J, Lejeune $\mathrm{M}$ : The immune response in nonmetastatic axillary lymph nodes is associated with the presence of axillary metastasis and breast cancer patient outcome. Am J Pathol 2020, 190:660-673

25. Callau C, Lejeune M, Korzynska A, Garcia M, Bueno G, Bosch R, Jaen J, Orero G, Salvado T, Lopez C: Evaluation of cytokeratin-19 in breast cancer tissue samples: a comparison of automatic and manual evaluations of scanned tissue microarray cylinders. Biomed Eng Online 2015, 14(Suppl 2):S2

26. Pinder SE, Brown JP, Gillett C, Purdie CA, Speirs V, Thompson AM, Shaaban AM: The manufacture and assessment of tissue microarrays: suggestions and criteria for analysis, with breast cancer as an example. J Clin Pathol 2013, 66:169-177

27. Pelekanou V, Villarroel-Espindola F, Schalper KA, Pusztai L, Rimm DL: CD68, CD163, and matrix metalloproteinase 9 (MMP-9) co-localization in breast tumor microenvironment predicts survival differently in ERpositive and -negative cancers. Breast Cancer Res 2018, 20:154

28. Muftah AA, Aleskandarany MA, Al-Kaabi MM, Sonbul SN, DiezRodriguez M, Nolan CC, Caldas C, Ellis IO, Rakha EA, Green AR: Ki67 expression in invasive breast cancer: the use of tissue microarrays compared with whole tissue sections. Breast Cancer Res Treat 2017, 164:341-348

29. Farahani N, Pantanowitz L: Overview of telepathology. Clin Lab Med 2016, 36:101-112

30. Fernandez-Carrobles Mdel M, Bueno G, Deniz O, Salido J, GarciaRojo M: Automatic handling of tissue microarray cores in highdimensional microscopy images. IEEE J Biomed Health Inform 2014, 18:999-1007

31. Roszkowiak L, Lopez C: PATMA: parser of archival tissue microarray. PeerJ 2016, 4:e2741

32. Lopez C, Lejeune M, Bosch R, Korzynska A, Garcia-Rojo M, Salvado MT, Alvaro T, Callau C, Roso A, Jaen J: Digital image analysis in breast cancer: an example of an automated methodology and the effects of image compression. Stud Health Technol Inform 2012, 179:155-171

33. Korzynska A, Neuman U, López C, Lejeune M, Bosch R. The method of immunohistochemical images standardization. Edited by Choras R. Berlin, Heidelberg: Springer, 2010. pp. 213-221

34. Korzynska A, Roszkowiak L, Zak J, Lejeune M, Orero G, Bosch R, López C: The METINUS Plus method for nuclei quantification in tissue microarrays of breast cancer and axillary node tissue section. Biomed Signal Process Control 2017, 32:1-9

35. Peduzzi P, Concato J, Kemper E, Holford TR, Feinstein AR: A simulation study of the number of events per variable in logistic regression analysis. J Clin Epidemiol 1996, 49:1373-1379

36. Vittinghoff E, McCulloch CE: Relaxing the rule of ten events per variable in logistic and Cox regression. Am J Epidemiol 2007, 165: $710-718$

37. Gibert-Ramos A, Lopez C, Bosch R, Fontoura L, Bueno G, GarciaRojo M, Berenguer M, Lejeune M: Immune response profile of primary tumour, sentinel and non-sentinel axillary lymph nodes related to metastasis in breast cancer: an immunohistochemical point of view. Histochem Cell Biol 2019, 152:177-193

38. Kohrt HE, Nouri N, Nowels K, Johnson D, Holmes S, Lee PP: Profile of immune cells in axillary lymph nodes predicts disease-free survival in breast cancer. PLoS Med 2005, 2:e284

39. He M, Zhang JX, Jiang YZ, Chen YL, Yang HY, Tang LC, Shao ZM, Di GH: The lymph node ratio as an independent prognostic factor for node-positive triple-negative breast cancer. Oncotarget 2017, 8: 44870-44880

40. Borges US, Costa-Silva DR, da Silva-Sampaio JP, EscorcioDourado CS, Conde AM Jr, Campelo V, Gebrim LH, da Silva BB, Lopes-Costa PV: A comparative study of Ki-67 antigen expression between luminal A and triple-negative subtypes of breast cancer. Med Oncol 2017, 34:156

41. Stathopoulos GP, Malamos NA, Markopoulos C, Polychronis A, Armakolas A, Rigatos S, Yannopoulou A, Kaparelou M, Antoniou P: The role of Ki-67 in the proliferation and prognosis of breast cancer molecular classification subtypes. Anticancer Drugs 2014, 25:950-957

42. Houvenaeghel G, Sabatier R, Reyal F, Classe JM, Giard S, Charitansky H, Rouzier R, Faure C, Garbay JR, Darai E, Hudry D, Gimbergues P, Villet R, Lambaudie E: Axillary lymph node micrometastases decrease triple-negative early breast cancer survival. Br J Cancer 2016, 115:1024-1031

43. Mando P, Rizzo M, de la Puente CP, Maino M, Ponce C, Pombo MT, Amat M, Costanzo MV, Nervo A, Nadal J, Fabiano V, Loza J, Loza CM, Colo F, Reinaldo C: High histologic grade and high Ki-67 expression predict phenotypic alterations in node metastasis in primary breast cancers. J Breast Cancer 2017, 20:170-175

44. Van Calster B, Vanden Bempt I, Drijkoningen M, Pochet N, Cheng J, Van Huffel S, Hendrickx W, Decock J, Huang HJ, Leunen K, Amant F, Berteloot P, Paridaens R, Wildiers H, Van Limbergen E, Weltens C, Timmerman D, Van Gorp T, Smeets A, Van den Bogaert W, Vergote I, Christiaens MR, Neven P: Axillary lymph node status of operable breast cancers by combined steroid receptor and HER-2 status: triple positive tumours are more likely lymph node positive. Breast Cancer Res Treat 2009, 113:181-187 
45. Lee JH, Kim SH, Suh YJ, Shim BY, Kim HK: Predictors of axillary lymph node metastases (ALNM) in a Korean population with T1-2 breast carcinoma: triple negative breast cancer has a high incidence of ALNM irrespective of the tumor size. Cancer Res Treat 2010, 42:30-36

46. Arvold ND, Taghian AG, Niemierko A, Abi Raad RF, Sreedhara M, Nguyen PL, Bellon JR, Wong JS, Smith BL, Harris JR: Age, breast cancer subtype approximation, and local recurrence after breastconserving therapy. J Clin Oncol 2011, 29:3885-3891

47. Dent R, Trudeau M, Pritchard KI, Hanna WM, Kahn HK, Sawka CA, Lickley LA, Rawlinson E, Sun P, Narod SA: Triple-negative breast cancer: clinical features and patterns of recurrence. Clin Cancer Res 2007, 13:4429-4434

48. Nguyen PL, Taghian AG, Katz MS, Niemierko A, Abi Raad RF, Boon WL, Bellon JR, Wong JS, Smith BL, Harris JR: Breast cancer subtype approximated by estrogen receptor, progesterone receptor, and HER-2 is associated with local and distant recurrence after breastconserving therapy. J Clin Oncol 2008, 26:2373-2378

49. Haffty BG, Yang Q, Reiss M, Kearney T, Higgins SA, Weidhaas J, Harris L, Hait W, Toppmeyer D: Locoregional relapse and distant metastasis in conservatively managed triple negative early-stage breast cancer. J Clin Oncol 2006, 24:5652-5657

50. Gangi A, Mirocha J, Leong T, Giuliano AE: Triple-negative breast cancer is not associated with increased likelihood of nodal metastases. Ann Surg Oncol 2014, 21:4098-4103

51. Corthay A: Does the immune system naturally protect against cancer? Front Immunol 2014, 5:197

52. Kim R, Emi M, Tanabe K: Cancer immunoediting from immune surveillance to immune escape. Immunology 2007, 121:1-14

53. Shou J, Zhang Z, Lai Y, Chen Z, Huang J: Worse outcome in breast cancer with higher tumor-infiltrating FOXP3+ Tregs: a systematic review and meta-analysis. BMC Cancer 2016, 16:687

54. Roncador G, Brown PJ, Maestre L, Hue S, MartinezTorrecuadrada JL, Ling KL, Pratap S, Toms C, Fox BC, Cerundolo V, Powrie F, Banham AH: Analysis of FOXP3 protein expression in human $\mathrm{CD} 4+\mathrm{CD} 25+$ regulatory $\mathrm{T}$ cells at the singlecell level. Eur J Immunol 2005, 35:1681-1691

55. Sisirak V, Faget J, Gobert M, Goutagny N, Vey N, Treilleux I, Renaudineau S, Poyet G, Labidi-Galy SI, Goddard-Leon S, Durand I, Le Mercier I, Bajard A, Bachelot T, Puisieux A, Puisieux I, Blay JY, Menetrier-Caux C, Caux C, Bendriss-Vermare N: Impaired IFNalpha production by plasmacytoid dendritic cells favors regulatory T-cell expansion that may contribute to breast cancer progression. Cancer Res 2012, 72:5188-5197

56. Treilleux I, Blay JY, Bendriss-Vermare N, Ray-Coquard I, Bachelot T, Guastalla JP, Bremond A, Goddard S, Pin JJ, Barthelemy-Dubois C, Lebecque S: Dendritic cell infiltration and prognosis of early stage breast cancer. Clin Cancer Res 2004, 10:7466-7474

57. Ito $\mathrm{T}$, Yang $\mathrm{M}$, Wang $\mathrm{YH}$, Lande R, Gregorio J, Perng OA, Qin XF, Liu YJ, Gilliet M: Plasmacytoid dendritic cells prime IL-10producing $\mathrm{T}$ regulatory cells by inducible costimulator ligand. $\mathrm{J}$ Exp Med 2007, 204:105-115

58. Catacchio I, Silvestris N, Scarpi E, Schirosi L, Scattone A, Mangia A: Intratumoral, rather than stromal, $\mathrm{CD} 8+\mathrm{T}$ cells could be a potential negative prognostic marker in invasive breast cancer patients. Transl Oncol 2019, 12:585-595

59. Matkowski R, Gisterek I, Halon A, Lacko A, Szewczyk K, Staszek U, Pudelko M, Szynglarewicz B, Szelachowska J, Zolnierek A, Kornafel J: The prognostic role of tumor-infiltrating CD4 and CD8 T lymphocytes in breast cancer. Anticancer Res 2009, 29:2445-2451

60. Macchetti AH, Marana HR, Silva JS, de Andrade JM, Ribeiro-Silva A, Bighetti S: Tumor-infiltrating CD4 $+\mathrm{T}$ lymphocytes in early breast cancer reflect lymph node involvement. Clinics 2006, 61:203-208
61. Yang J, Li X, Liu X, Liu Y: The role of tumor-associated macrophages in breast carcinoma invasion and metastasis. Int J Clin Exp Path 2015, 8:6656-6664

62. McKiernan E, McDermott EW, Evoy D, Crown J, Duffy MJ: The role of S100 genes in breast cancer progression. Tumour Biol 2011, $32: 441-450$

63. Bodey B, Siegel SE, Kaiser HE: Antigen presentation by dendritic cells and their significance in antineoplastic immunotherapy. In Vivo 2004, 18:81-100

64. Hu G, Wang S: Prognostic role of tumor-infiltrating CD57-positive lymphocytes in solid tumors: a meta-analysis. Oncotarget 2018, 9 : $8111-8119$

65. Rezaeifard S, Safaei A, Talei A, Faghih Z, Erfani N: NK, NKT and invariant-NKT cells in tumor draining lymph nodes of patients with breast cancer. Iran J Immunol 2019, 16:291-298

66. Mahmoud SM, Paish EC, Powe DG, Macmillan RD, Grainge MJ, Lee AH, Ellis IO, Green AR: Tumor-infiltrating CD8+ lymphocytes predict clinical outcome in breast cancer. J Clin Oncol 2011, 29: 1949-1955

67. Rathore AS, Kumar S, Konwar R, Makker A, Negi MP, Goel MM: $\mathrm{CD} 3+, \mathrm{CD} 4+\& \mathrm{CD} 8+$ tumour infiltrating lymphocytes (TILs) are predictors of favourable survival outcome in infiltrating ductal carcinoma of breast. Indian J Med Res 2014, 140:361-369

68. Huang Y, Ma C, Zhang Q, Ye J, Wang F, Zhang Y, Hunborg P, Varvares MA, Hoft DF, Hsueh EC, Peng G: CD4 + and CD8+ T cells have opposing roles in breast cancer progression and outcome. Oncotarget 2015, 6:17462-17478

69. Matsumoto H, Thike AA, Li H, Yeong J, Koo SL, Dent RA, Tan PH, Iqbal J: Increased CD4 and CD8-positive T cell infiltrate signifies good prognosis in a subset of triple-negative breast cancer. Breast Cancer Res Treat 2016, 156:237-247

70. Oh E, Choi YL, Park T, Lee S, Nam SJ, Shin YK: A prognostic model for lymph node-negative breast cancer patients based on the integration of proliferation and immunity. Breast Cancer Res Treat 2012, 132:499-509

71. Characiejus D, Pasukoniene V, Kazlauskaite N, Valuckas KP, Petraitis T, Mauricas M, Den Otter W: Predictive value of CD8highCD57+ lymphocyte subset in interferon therapy of patients with renal cell carcinoma. Anticancer Res 2002, 22:3679-3683

72. Characiejus D, Pasukoniene V, Jonusauskaite R, Azlauskaite N, Aleknavicius E, Mauricas M, Otter WD: Peripheral blood CD8highCD57+ lymphocyte levels may predict outcome in melanoma patients treated with adjuvant interferon-alpha. Anticancer Res 2008, 28:1139-1142

73. Akagi J, Baba H: Prognostic value of CD57(+) T lymphocytes in the peripheral blood of patients with advanced gastric cancer. Int J Clin Oncol 2008, 13:528-535

74. Sze DM, Brown RD, Yuen E, Gibson J, Ho J, Raitakari M, Basten A, Joshua DE, Fazekas de St Groth B: Clonal cytotoxic T cells in myeloma. Leuk Lymphoma 2003, 44:1667-1674

75. Van den Hove LE, Vandenberghe P, Van Gool SW, Ceuppens JL, Demuynck H, Verhoef GE, Boogaerts MA: Peripheral blood lymphocyte subset shifts in patients with untreated hematological tumors: evidence for systemic activation of the $\mathrm{T}$ cell compartment. Leuk Res 1998, 22:175-184

76. Schreiber RD, Old LJ, Smyth MJ: Cancer immunoediting: integrating immunity's roles in cancer suppression and promotion. Science 2011, $331: 1565-1570$

77. Iwamoto M, Shinohara H, Miyamoto A, Okuzawa M, Mabuchi H, Nohara T, Gon G, Toyoda M, Tanigawa N: Prognostic value of tumor-infiltrating dendritic cells expressing CD83 in human breast carcinomas. Int J Cancer 2003, 104:92-97 